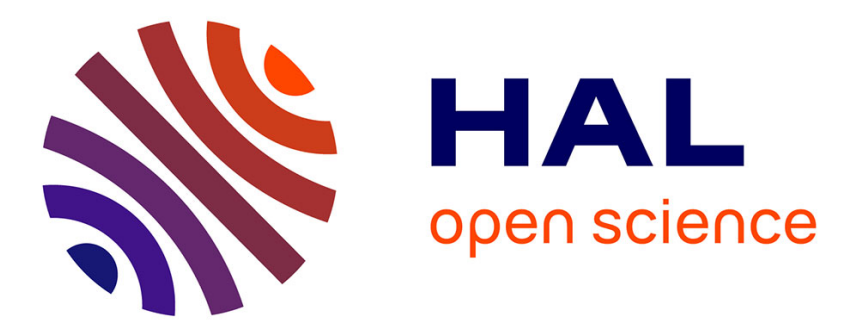

\title{
Plasma afterglow-assisted oxidation of iron-copper bilayers
}

\author{
A. Imam, T. Gries, H. Sezen, M. Amati, D. Mangin, T. Belmonte
}

\section{To cite this version:}

A. Imam, T. Gries, H. Sezen, M. Amati, D. Mangin, et al.. Plasma afterglow-assisted oxidation of iron-copper bilayers. Nano-Structures and Nano-Objects, 2016, 7, pp.41-48. 10.1016/j.nanoso.2016.06.003 . hal-02113598

\section{HAL Id: hal-02113598 \\ https://hal.science/hal-02113598}

Submitted on 14 May 2019

HAL is a multi-disciplinary open access archive for the deposit and dissemination of scientific research documents, whether they are published or not. The documents may come from teaching and research institutions in France or abroad, or from public or private research centers.
L'archive ouverte pluridisciplinaire HAL, est destinée au dépôt et à la diffusion de documents scientifiques de niveau recherche, publiés ou non, émanant des établissements d'enseignement et de recherche français ou étrangers, des laboratoires publics ou privés. 


\title{
Plasma afterglow-assisted oxidation of iron-copper bilayers
}

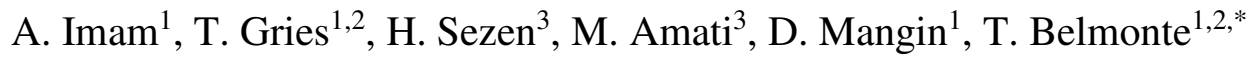 \\ ${ }^{1}$ Université de Lorraine, Institut Jean Lamour, UMR CNRS 7198, NANCY, F-54042, France \\ ${ }^{2}$ CNRS, Institut Jean Lamour, UMR CNRS 7198, NANCY, F-54042, France \\ ${ }^{3}$ Elettra - Sincrotrone Trieste S.C.p.A. S.S. 14 Km 163,5 in AREA Science Park, 34149 \\ Basovizza, Trieste, Italy \\ * corresponding author. Email: thierry.belmonte@univ-lorraine.fr
}

PACS number: 81.07. \pm b Nanoscale materials and structures: fabrication and characterization

Keywords: $\mathrm{CuO} ; \mathrm{Fe}_{2} \mathrm{O}_{3}$; $\mathrm{Cu} / \mathrm{Fe}$ stacks ; Nanostructuration ; Afterglow ; Oxidation 


\begin{abstract}
Iron layers with variable thicknesses, deposited onto copper thin films, are oxidized by a plasma afterglow at atmospheric pressure. Such a bilayer arrangement enables the growth of caterpillar-like patterns covered by $\mathrm{CuO}$ and $\mathrm{Fe}_{2} \mathrm{O}_{3}$ nanostructures. Two main mechanisms are at stake: either copper comes up to the surface through cracks or boundaries between the columns of the coating, or it diffuses through parts of the $\mathrm{Fe}_{2} \mathrm{O}_{3}$ layer made permeable by tensile stress. Structures grown by the former mechanisms are characterized by a central channel, whereas those grown by the latter exhibit a plane interface above which stands an equiaxed grain heap. This result was used to localize the growth of nanowires in cracks formed priory to the afterglow-assisted treatment. By resorting to XPS microscopy experiments carried out with the scanning photoelectron microscope at the ESCAMicroscopy beamline of the Elettra synchrotron facility in Trieste, we could gain access to the surface composition of a single isolated pattern.
\end{abstract}

\title{
HIGHLIGHTS
}

- Iron-copper bilayers are deposited by magnetron sputtering

- Bilayers are oxidized by plasma afterglow at atmospheric pressure

- Caterpillar-like patterns covered by $\mathrm{CuO}$ and $\mathrm{Fe}_{2} \mathrm{O}_{3}$ nanostructures are formed

- Copper comes up through cracks or $\mathrm{Fe}_{2} \mathrm{O}_{3}$ layer made permeable by tensile stress

- Localizing nanowires is achievable by creating crack patterns before oxidation. 


\section{INTRODUCTION}

Growing tailored oxide nanostructures is of major importance in some applications like water splitting [1-3] or catalysis [4-6]. It might be useful to control the way a surface could be patterned by nanostructures with well-defined properties. Resorting to non-equilibrium media, like direct plasmas or afterglows, opens up new opportunities to control the synthesis of nanostructures [7]. In direct low-pressure plasma processes, sputtering mechanisms can be partly responsible for the growth of nanostructures [8-10]. In plasma afterglow processes, oxygen atoms or metastable states of oxygen - mainly the singlet state $\mathrm{O}_{2}\left(\mathrm{a}^{1} \Delta_{\mathrm{g}}\right)$ - are available. They are more active than ground state oxygen at low temperature because of the extra amount of energy coming from dissociation or excitation. As low-temperature oxidation favours anisotropic crystal growth, and thus, the synthesis of nanostructures, non-equilibrium media promotes the growth of oxide nanostructures [11-16].

In a recent work [17], we showed that mixing iron and copper in alloy thin films strongly affects the growth processes of nanostructures, leading to original shapes. Oxidation of copper, because it is slower than iron, is strongly anisotropic, leading easily to nanostructures. Increasing the amount of iron decreases the level of stress in the film and hinders but never stops the access of copper to the topmost surface.

Thermal oxidation of brass alloys in air was investigated by Zhu et al. [18]. They could simultaneously synthesize $\mathrm{ZnO}-\mathrm{CuO}$ nanostructures between 623 and $813 \mathrm{~K}$. By varying the brass composition, 1D nanowires/nanoflakes, 2D nanosheets, and 3D networks could be grown. Another group studied the influence of the oxygen partial pressure [19] and found that the compressive growth stress causes the plastic deformation of oxide scale and increases dislocation defects in scale, which is of benefit to the growth of nanowires and nanowalls. In a previous paper [20], the same authors described that the increase in oxidation temperature from 773 to $873 \mathrm{~K}$ typically increases the compressive growth stress. As plastic deformation is easier in the substrate than that in the oxide scale, buckling-induced patterns decrease in 
size, whereas micro-cracks form in the oxide scale. Micro-cracks act as short-circuits, resulting in the formation of flower-like nanostructures.

Finally, let's mention that radiofrequency plasma-assisted oxidation of brass was reported [21] but no nanostructures were formed in the studied conditions.

In the present work, we investigate the role of an iron thin film with variable thickness on the access of copper to the topmost surface. $\mathrm{Fe} / \mathrm{Cu}$ bilayers are oxidizing with an $\mathrm{Ar}-\mathrm{O}_{2}$ plasma afterglow operating at atmospheric pressure. $\mathrm{Cu} / \mathrm{Fe}$ bilayers were also investigated but the corresponding results are not reported hereinafter, in so far as thus-grown nanostructures are similar to those formed with $\mathrm{Cu}$-rich alloys and reported in reference [17].

\section{EXPERIMENTAL SET-UP}

The experimental set-up was described in details elsewhere [17]. Briefly, an atmospheric Ar$\mathrm{O}_{2}$ microwave plasma was ignited in a fused silica tube (27 $\mathrm{mm}$ inner diameter) placed in a $2.45 \mathrm{GHz}$ resonant cavity. The power absorbed by the plasma was $100 \mathrm{~W}$. Flow rates of gases were controlled by mass flow controllers and the total flow rate was $275 \mathrm{sccm}$ (standard cubic centimeter per minute). The partial pressure of oxygen in the gas mixture was set at 9.1 vol.\%. The treatment time was 2 hours to get sufficiently long structures to identify and characterize them as clearly as possible. The micro-afterglow was visible as a light beam escaping a hole (500 $\mu \mathrm{m}$ in diameter) drilled in a brass plate screwed on one wall of the cavity [11]. Oxidizing active species in the afterglow are mainly $\mathrm{O}, \mathrm{O}_{2}(\mathrm{a})$ and $\mathrm{O}_{2}(\mathrm{X})$ because the afterglow is too hot to allow the formation of $\mathrm{O}_{3}[12]$.

A detailed thermal analysis reported in reference [17] showed that the maximum treatment temperature is about $733 \mathrm{~K}$. When the plasma afterglow hits the metallic surface, it oxidizes concentric areas that extend radially up to several millimetres. Because of the temperature radial gradient that prevails in such conditions, $\mathrm{Fe} / \mathrm{Cu}$ thin films, when submitted to the afterglow treatment, produce different nanostructures from the centre of the treatment outward, for a given thickness ratio. 
Samples were Fe/Cu films deposited by DC magnetron sputtering. Thicknesses of copper and iron layers were set by adjusting the deposition time. The thickness of the bilayer was $1.3 \mu \mathrm{m}$. The iron layer, always deposited onto the copper layer, had thicknesses of 50, 155 and 900 $\mathrm{nm}$. The base vacuum in the sputtering chamber is $5 \times 10^{-6}$ mbar. The distance between the sample, made of fused silica, and the targets $(50 \mathrm{~mm}$ in diameter, $3 \mathrm{~mm}$ thick and $>99.99 \%$ purity for $\mathrm{Cu}$ target and $0.25 \mathrm{~mm}$ and $99.5 \%$ purity for Fe target) was $100 \mathrm{~mm}$. The substrateholder rotated at 28 revolutions per minute during deposition to ensure homogeneity. Thin films were deposited at a pressure of $5.8 \times 10^{-3}$ mbar in a 10 vol\% $\mathrm{H}_{2}-90$ vol\% Ar mixture.

Treated surfaces were characterized by several surface diagnostics. Scanning Electron Microscopy (SEM) was made with a Philips XL 30. X-ray diffraction using $\mathrm{Cu}-\mathrm{K} \alpha$ radiation $(\lambda=0.179026 \mathrm{~nm})$ was performed with a Bruker D8 Discover diffractometer.

A CAMECA IMS 7F instrument was used for Secondary Ion Mass Spectrometry (SIMS). A $\mathrm{Cs}^{+}$primary ion beam of $30 \mathrm{nA}$ operating at $5 \mathrm{kV}$ was used to sputter sample with an impact energy of $3 \mathrm{keV}$. Mass Resolving Power was set to 2000. Depth-profiles were acquired over an area of $100 \times 100 \mu \mathrm{m}^{2}$.

The XPS microscopy experiments were carried out with the scanning photoelectron microscope (SPEM) at the ESCAMicroscopy beamline at the Elettra synchrotron facility in Trieste, Italy. In SPEM, the incident x-ray beam, with $648.5 \mathrm{eV}$ photon energy, is focused on the sample to a spot of $130-150 \mathrm{~nm}$ diameter using zone plate optics. The sample is then scanned under the focused beam. The highest cross-section peaks of $\mathrm{Cu} 2 \mathrm{p}$ and Fe $2 \mathrm{p}$ are not accessible with such a photon energy, but $\mathrm{Cu} 3 \mathrm{p}$ and $\mathrm{Fe} 3 \mathrm{p}$ could be acquired. The SPEM instrument has two operation modes, microprobe photoelectron spectroscopy and spectromicroscopy imaging. The microprobe spectroscopy mode is identical to conventional XPS spectroscopy, i.e. energy distribution curves are measured from the selected area illuminated by a $130 \mathrm{~nm}$ focused beam with a $0.2 \mathrm{eV}$ spectral resolution. The imaging mode maps the surface distribution of elements by collecting photoelectrons with a selected energy 
window while scanning the specimen with respect to the focused beam. More details about the instrument can be found in reference [22].

\section{RESULTS AND DISCUSSION}

\subsection{Layer and patterns structures}

In figure 1, a map of the different nanostructures obtained with the afterglow process for iron thicknesses ranging from 50 to $900 \mathrm{~nm}$ is depicted. Four main types of nano-objects are found: $\mathrm{Fe}_{2} \mathrm{O}_{3}$ nanoblades, $\mathrm{CuO}$ nanowalls, nanotowers and nanowires. These nano-objects are described in details in [17]. Briefly, $\mathrm{CuO}$ nanowalls are characterized by their thickness, which is much larger than $\mathrm{Fe}_{2} \mathrm{O}_{3}$ nanoblades $(\sim 50 \mathrm{~nm}$ vs $\sim 10 \mathrm{~nm})$, their height, which is always lower than nanoblades for given conditions, and by the existence of amorphous domains embedded in a crystalline matrix (which is not observed with $\mathrm{Fe}_{2} \mathrm{O}_{3}$ nanoblades). Nanotowers are an assembly of two nanowires with an amorphous phase in between. When the width of the nanostructure shrinks, large steps appear, producing a serrated shape as in a tower. $\mathrm{CuO}$ nanowires with diameters as small as $5 \mathrm{~nm}$ are also obtained.

The presence of the iron layer on top of the copper layer leads to the formation of caterpillarlike patterns (figures $\mathbf{2}$ and 3), especially in the external part of the radial distribution (figure 1). In figure 2 , we show that each caterpillar-like pattern can be covered by different types of nanostructures, as indicated in figure 1 , i.e. $\mathrm{Fe}_{2} \mathrm{O}_{3}$ nanoblades, $\mathrm{CuO}$ nanowalls, nanotowers and nanowires, depending on the temperature. $\mathrm{Fe}_{2} \mathrm{O}_{3}$ nanoblades are very easy to distinguish from other nanostructures, which makes finally all nanostructures easily recognizable.

Patterns get sparser and shorter when thickness of the iron layer is increased. It is important to consider that patterns only appear if the temperature is low enough, which seems to depend also on the initial iron thickness. Indeed, in figure 1, the minimum radial distance beyond which patterns appear, changes with the initial iron thickness. The relationship between patterns and cracks is tricky. First, patterns without cracks can be found (figure 3a). Next, if the iron layer is thin, large areas can be covered by uncorrelated patterns and cracks (figure 
3b). However, at some places, patterns can also be split into 2 parts (figure 3c) or crossed by a crack that propagates in the film. Then, some cracks are formed after the synthesis of patterns. Finally, if the iron layer is thick, large areas are mainly (but not only) covered by strongly-correlated patterns and cracks (figure 3d). From figure 4, we readily understand that for a very thin iron layer $(50 \mathrm{~nm})$ patterns grow along the boundaries that separate the columns of the sputtered $\mathrm{Cu}$ layer. Then, copper has an easier access to the surface through these boundaries that go through the thin iron layer as well. So, if the iron layer is thin (50 $\mathrm{nm})$, it does not stop the outward diffusion of copper, which occurs at column boundaries. If it is very thick (900 nm), copper can more easily reach the surface through cracks. If it is in between these two situations $(155 \mathrm{~nm})$, diffusion at column boundaries is limited. Then, the transport of copper to the surface can still occur by diffusion through cracks but, because of the possibility to find patterns without cracks, another mechanism must hold. This mechanism, which is limited but still exists if the layer is very thick, is discussed hereinafter. The presence of $\mathrm{Fe}_{2} \mathrm{O}_{3}$ nanoblades when the iron layer is thick enough is simply due to its oxidation, iron being then readily available.

SEM cross-section views of caterpillar-like patterns, obtained after a two-hour oxidation performed on a $155 \mathrm{~nm} \mathrm{Fe} / \mathrm{Cu}$ coating, show common features and specificities (figure 5). To describe them, we need to refer to figure $\mathbf{6}$ where the different possible layers are designed by segments. From the interface with the silica wafer to the top of the oxide layer, we observe:

- a cell-like layer (denoted $[\mathrm{AB}]$ in figure 6)

- a fine grain columnar layer (segment $[\mathrm{BC}]$ ), often divided into two parts by a line made of separated spherical holes (segments $\left[\mathrm{BB}^{\prime}\right]$ and $\left[\mathrm{B}^{\prime} \mathrm{C}\right]$ )

- and protruding structure (segment $[\mathrm{CD}]$ )

When a caterpillar-like pattern is found, the protruding structure $[C D]$ can be made of:

- a large grain columnar heap (segment [CC"]), which is not always present

- a fine grain layer (segment $\left.\left[\mathrm{CC}^{\prime}\right]\right)$ 
- a topmost thin layer where nanowires are embedded [C'D'] (figure 6)

- $\quad$ sometimes topped by nanowires [D'D] (figures 5a to 5c and figure 6)

Among the features common to all patterns, the presence of a cell-like layer $[\mathrm{AB}]$ is observed everywhere, but in figure 5c and in figure 6, this layer, which is visible on one side of the image, adopt a special structure under the pattern. Then, aligned large grains are observed. Layer $[\mathrm{BC}]$ is no longer a fine grain columnar layer, but an ultrafine grain layer (figures 5c and 6). In these two cases, an equiaxed grain heap [CC"] is also visible. The presence of a central channel - also visible in layer $[\mathrm{AB}]$ - as in figures $\mathbf{5 a}$ and $\mathbf{5 b}$ is replaced by a plane interface extending all along the heap. The radial distribution of the grains in layer [CC'], which is strongly marked in figure 5a, gives way to an almost equiaxed growth.

We could also observe the transverse structure (i.e. perpendicular to the surface and parallel to the pattern axis) of one pattern exhibiting a central channel (figure 7a). Regularly-spaced channels are also observed crosswise, as if the central feeding channel was cut into pieces, each of them feeding the pattern over a certain distance $(\sim 1 \mu \mathrm{m}$ in figure $7 \mathbf{b})$.

\subsection{Diagnostics results}

In figure 8, SIMS results recorded every millimetre from the centre of a treated sample outward are provided. They give very accurate results in perfect agreement with SEM images. Normalized intensities of $\mathrm{Cu}, \mathrm{Fe}$ and O SIMS signals are depicted as a function of depth defined with respect to the interface between layer and silica. The sputtering time of the oxidized layer by the argon beam cannot be simply converted into a thickness scale because of the strong composition, density and structure changes through the layer. We also chose to present raw intensities, and not composition, the oxygen signal being difficult to interpret in terms of oxidation levels of each metallic element. This is due to the specificity of the SIMS technique where the emission yield of one element is strongly affected by its environment. Besides, the porosity likely affects raw intensities all over the sample depth. 
$\mathrm{Cu}$ and $\mathrm{Fe}$ signals evolve strongly according to the radial position. As the temperature decreases from the centre of the treatment outward, the farthest spots are less oxidized. At +4 $\mathrm{mm}$ and $+3 \mathrm{~mm}$, an outer iron oxide layer covers a hardly-oxidized $\mathrm{Cu}$ layer. Nanostructures are too small to affect significantly the SIMS profile at the chosen sputtering rate. At $+2 \mathrm{~mm}$, the fine grain columnar layer $[\mathrm{BC}]$ is characterized by a Gaussian distribution of iron associated with depletion in copper that diffuses outward. At $+1 \mathrm{~mm}$, fine grain layer segment $\left[C^{\prime}\right]$ is characterized by a weak SIMS intensity of iron in copper. The topmost thin layer [C'D'] is made of pure copper oxide and the nanowires start being long enough to contribute significantly to the SIMS signal, leading to the [D'D] segment. At the centre, the same layers are observed. A change in the proportion of $\mathrm{Cu}$ and $\mathrm{Fe}$ in the $[\mathrm{BC}]$ segment shows an inflection point on the oxygen profile, which might be attributed to the presence of spherical holes that form a well-visible separation line between [BB'] and [B'C] layers. Because of the size of the SIMS spot used to diagnose the surface composition $\left(100 \times 100 \mu \mathrm{m}^{2}\right)$, patterns would only weakly contribute to the whole signal. Then, the equiaxed grain heap [C'C"] does not appear in the SIMS profiles.

Space-resolved XRD patterns are depicted in figure 9. No spinel phases $\left(\mathrm{CuFeO}_{2}, \mathrm{CuFe}_{2} \mathrm{O}_{4}\right.$ or $\mathrm{Cu}_{6} \mathrm{Fe}_{3} \mathrm{O}_{7}$ ) are observed in our conditions. Only $\mathrm{Fe}_{2} \mathrm{O}_{3}$ and $\mathrm{CuO}$ are found. The lack of $\mathrm{FeO}$ is likely due to the disproportionation of this phase into iron and $\mathrm{Fe}_{3} \mathrm{O}_{4}$, which occurs below $850 \mathrm{~K}$.

We could perform spatially resolved XPS measurements on isolated patterns which is $3 \mathrm{~mm}$ away from centre of the treatment. The spectrum acquired on the film, beside the pattern (point $\mathrm{O}$ in figure 10) shows comparable amounts of iron and copper. The presence of iron on the topmost surface is consistent with SIMS profile given at this distance (figure 8). Traces of zinc (due to contamination during the sputtering process) and silicon (from the substrate) are also observed. Zinc was not sought in SIMS measurements, but silicon was. Results (available on demand) show that, at $3 \mathrm{~mm}$ from the centre, the ${ }^{133} \mathrm{Cs}^{28} \mathrm{Si}$ signal is null at the topmost 
surface, reaches $\sim 30$ counts after $750 \mathrm{~s}$ of $\mathrm{Ar}^{+}$sputtering, close to the initial interface between $\mathrm{Fe}$ and $\mathrm{Cu}$, decays to zero after $1500 \mathrm{~s}$, and increases again after $2000 \mathrm{~s}$ to reach its maximal value in the silica substrate with $\sim 2800$ counts. So, we infer that the relatively high intensity of the silicon contribution found in the XPS spectra is due to local cracks that open access to the substrate. Indeed, it would be extremely surprising to observe an outward transport of silicon, trapped in the form of silica, to the top of layer.

Both patterns exhibit almost identical spectra, which show a different stoichiometry in respect to the substrate, this latter being richer in iron content. Zinc and oxygen are also different on the patterns and on the film. More oxygen and more zinc are found on the substrate than on the pattern. Main contribution for a higher amount of $\mathrm{O} 1 \mathrm{~s}$ intensity on the film is the presence of relatively higher amount of silica. In addition, the larger amount of iron oxide on the surface of the substrate, $\mathrm{Fe}_{2} \mathrm{O}_{3}$ containing 60 at.\% of oxygen versus 50 at. $\%$ only for $\mathrm{CuO}$. We find, as predicted by the Ellingham diagram, that zinc is easier to oxidize than iron and copper. The two former elements oxidize first and, as they are trapped, are found at negligible concentration in $\mathrm{CuO}$ patterns that are formed in a second step. So, the role of zinc as trace contaminant is likely to be negligible.

\subsection{Growth mechanism of patterns}

By gathering the previous results, we obtain a relatively clear view of the way patterns grow in our conditions. Patterns are mainly made of $\mathrm{CuO}$ and may contain an amount iron that is all the larger as the distance from the centre is long. Copper has to find way to the topmost surface through the iron oxide layer that forms first. This occurs by outward diffusion of copper ions [11], either via a central channel if the $\mathrm{Fe}_{2} \mathrm{O}_{3}$ layer is blocking, which requires that the temperature be below a certain threshold or that the layer be thick enough, or via a locally-permeable $\mathrm{Fe}_{2} \mathrm{O}_{3}$ layer. Indeed, the growth rate of nanostructures scales as the square root of time because ion transportation is controlled by outward diffusion. The development of an inner porosity is due to this phenomenon, diffusion ions leaving vacancies behind them 
that coarsen to produce voids at the interface with the substrate. What is meant here by permeable is the loss of the diffusion barrier property of the layer, likely because of the increase in the number of voids per unit volume [23, 24]. In the former mechanism, the central channel is either a boundary between two columns (figure 4), which requires a thin $\mathrm{Fe}_{2} \mathrm{O}_{3}$ layer $(50 \mathrm{~nm})$, or a crack (figure 3d) if the $\mathrm{Fe}_{2} \mathrm{O}_{3}$ layer is thick $(900 \mathrm{~nm}$ ). In the latter mechanism, the growth of the pattern is characterized by a plane interface through which copper ions diffuse (figures $\mathbf{5 c}$ and $\mathbf{6}$ ). In this case, a specific structure, characterized by equiaxed grain heap, is found. The cell-like layer adopts a special structure with aligned large grains, whereas layer $[\mathrm{BC}]$ is no longer a fine grain columnar layer, but an ultrafine grain layer (figures 5c and 6). This transformation of layer $[\mathrm{BC}]$ is likely responsible for the diffusion, thus made possible, of copper ions. Over a short distance of 1-1.5 $\mu \mathrm{m}$, this barrier layer is made permeable. We propose that the mechanism leading to this change is due to the local development of a high tensile stress in this part of the layer. As shown in reference [23], normal tensile stresses are generated at both the metal-oxide interface (here the $\mathrm{Cu} / \mathrm{Fe}_{2} \mathrm{O}_{3}$ interface) and metal grain boundaries (here in copper). Those stresses are believed to be one of the important driven forces for oxide spallation. Besides, it has been pointed out that tensile forces are the cause of void nucleation by multi-axial stress field [24]. This would explain why a line made of separated spherical holes is observed within layer [BC]. The post-mortem formation of cracks is an indirect proof of the tensile stress that develops in the coating. The fact that they are most often aligned with patterns suggests that switching from one mechanism to the other is ruled by a threshold in the stress level beyond which cracks open, making the diffusion process change radically. This leads to a change in the structure of the cell-like layer, as mentioned previously. To our opinion, the cell-like structure would be made of an iron oxide skeleton, the cells, once copper starts leaving the layer. Iron would stay in this layer as an oxide under the shape of cell walls. However, this assertion still awaits proof. 
If the transport of copper is not limited, either because the temperature is high enough, or because the thickness of the iron layer is sufficiently weak to let copper reach the surface within a period of time inferior to the treatment duration, copper oxide nanostructures (nanowalls and nanotowers, mainly) develop spontaneously. The growth mechanisms of these peculiar objects are the same as those already observed for $\mathrm{Cu}-\mathrm{Fe}$ alloys described in a former paper of ours [17]. The reason for the similarity comes from the way copper and iron segregate in these alloys and form stacks of oxide layers that are very similar to those depicted here (e.g. in figure 8). So, the reader is referred to this work for a detailed analysis of the growth mechanisms of these nano-objects.

\subsection{Localized growth of nanostructures}

When a substrate, coated by another material, is sufficiently bent, regularly-spaced cracks are formed in the coating [25]. The oxidation process was applied to $300 \mathrm{~nm} \mathrm{Fe} / \mathrm{Cu}$ stack deposited on a $500 \mu \mathrm{m}$-thick silicon rectangle priory bent to form crack patterns (figure 11a). Cracks could have been opened by any other method (like indentation for instance). Nanowires grow almost exclusively in cracks (figure 11b). This feature does not depend on the orientation of the cracks (figures 11c and 11d). So, we can claim that we have found a way to localize nanowires on a surface.

\section{CONCLUSION}

We showed that the growth of oxides from $\mathrm{Fe} / \mathrm{Cu}$ bilayer coatings makes possible the synthesis of a large number of nanostructures. Besides nanowalls, nanotowers and nanowires, the formation mechanisms of caterpillar-like patterns covered by $\mathrm{CuO}$ and/or $\mathrm{Fe}_{2} \mathrm{O}_{3}$ nanostructures have been clarified. Two main mechanisms are at stake: either copper comes up to the surface through cracks or boundaries between the columns of the coating, or it diffuses through parts of the $\mathrm{Fe}_{2} \mathrm{O}_{3}$ layer made permeable by tensile stress. The possibility to grow locally patterns covered by nanostructures opens up new opportunities to localize nanostructures on a substrate. For instance, nanoindentation might be advantageously 
employed to control "locally" the generation of stress in the metallic films. These structures might be also useful to develop sensors integrating several possible responses to given molecules that could react either with $\mathrm{Fe}_{2} \mathrm{O}_{3}$ or $\mathrm{CuO}$ nanostructures. Ongoing attempts to increase the temperature are achieved to check the possibility of growing spinel phases in the $\mathrm{Fe}-\mathrm{Cu}-\mathrm{O}$ system. 


\section{REFERENCES}

[1] J. Su, L. Guo, N. Bao, C. A. Grimes, Nanostructured $\mathrm{WO}_{3} / \mathrm{BiVO}_{4}$ heterojunction films for efficient photoelectrochemical water splitting, Nano Lett. 11 (2011) 1928-1933

[2] J. Z. Zhang, Metal oxide nanomaterials for solar hydrogen generation from photoelectrochemical water splitting, MRS bulletin 36 (2011) 48-55

[3] Y. Lin, G. Yuan, R. Liu, S. Zhou, S. W. Sheehan, D. Wang, Semiconductor nanostructure-based photoelectrochemical water splitting: A brief review, Chem. Phys. Lett. 507 (2011) 209-215

[4] L. S. Zhong, J. S. Hu, H. P. Liang, A. M. Cao, W. G. Song, L. J. Wan, Self-Assembled 3D flowerlike iron oxide nanostructures and their application in water treatment, Adv. Mater. 18 (2006) 2426-2431.

[5] B. L. Kniep, T. Ressler, A. Rabis, F. Girgsdies, M. Baenitz, F. Steglich, R. Schlögl, Rational design of nanostructured copper-zinc oxide catalysts for the steam reforming of methanol, Angew. Chem. Int. Ed. 43 (2004) 112-115

[6] V. Polshettiwar, B. Baruwati, R. S. Varma, Self-assembly of metal oxides into threedimensional nanostructures: synthesis and application in catalysis, ACS Nano 3 (2009) $728-736$

[7] K. Ostrikov, E.C. Neyts, M. Meyyappan, Plasma nanoscience: from nano-solids in plasmas to nano-plasmas in solids, Adv. Phys. 62 (2013) 113-224

[8] U. Cvelbar, Towards large-scale plasma-assisted synthesis of nanowires, J. Phys. D: Appl. Phys. 44 (2011) 174014

[9] U. Cvelbar, K. Ostrikov, I. Levchenko, M. Mozetic, M. K. Sunkara, Control of morphology and nucleation density of iron oxide nanostructures by electric conditions on iron surfaces exposed to reactive oxygen plasmas, Appl. Phys. Lett., 94 (2009) 211502 
[10] K. Ostrikov, I. Levchenko, U. Cvelbar, M. Sunkara, M. Mozetic, From nucleation to nanowires: a single-step process in reactive plasmas, Nanoscale, 2 (2010). 2012-2027

[11] A. Altaweel, G. Filipič, T. Gries, T. Belmonte, Controlled growth of copper oxide nanostructures by atmospheric pressure micro-afterglow, J. Cryst. Growth, 407 (2014) $17-24$

[12] G. Arnoult, R.P. Cardoso, T. Belmonte, G. Henrion, Flow transition in a small scale microwave plasma jet at atmospheric pressure, Appl. Phys. Lett., 93 (2008) 191507

[13] G. Arnoult, T. Belmonte, F. Kosior, M. Dossot, G. Henrion, On the origin of selforganization of $\mathrm{SiO}_{2}$ nanodots deposited by CVD enhanced by atmospheric pressure remote microplasma, J. Phys. D: Appl. Phys., 44 (2011) 174022

[14] G. Arnoult, T. Belmonte, G. Henrion, Self-organization of $\mathrm{SiO}_{2}$ nanodots deposited by chemical vapor deposition using an atmospheric pressure remote microplasma, Appl. Phys. Lett., 96 (2010) 101505

[15] D. Kuete Saa, R.P. Cardoso, F. Kosior, A. Altaweel, T. Gries, S. Laminsi, T. Belmonte, Growth of ruthenium dioxide nanostructures by micro-afterglow oxidation at atmospheric pressure , Surf. Coat. Technol., 255 (2014) 3-7

[16] G. Arnoult, T. Gries, G. Henrion, S. Migot, V. Fournée, T. Belmonte, Localized growth of silicon oxide nanowires by micro-afterglow oxidation, Plasma Process. Polym., 9 (2012) 1125-1131

[17] A. Imam, A. Boileau, T. Gries, J. Ghanbaja, D. Mangin, K. Hussein, H.Sezen, M. Amati, T. Belmonte, Nanostructures design by plasma afterglow-assisted oxidation of ironcopper thin films, J. Cryst. Growth 442(2016) 52-61

[18] Y. Zhu, C.-H. Sow, T. Yu, Q. Zhao, P. Li, Z. Shen, D. Yu, J. T.-L. Thong, Co-synthesis of $\mathrm{ZnO}-\mathrm{CuO}$ nanostructures by directly heating brass in air, Adv. Funct. Mater. 16 (2006) 2415-2422 
[19] C. H. Xu, Z. B. Zhu, H. F. Lui, C. Surya, S. Q. Shi, The effect of oxygen partial pressure on the growth of $\mathrm{ZnO}$ nanostructure on $\mathrm{Cu}_{0.62} \mathrm{Zn}_{0.38}$ brass during thermal oxidation, Superlattices Microstruct. 49 (2011) 408-415

[20] C. H. Xu, Z. B. Zhu, G. L. Li, W. R. Xu, H. X. Huang, Growth of ZnO nanostructure on Cu0.62Zn0.38 brass foils by thermal oxidation, Mater. Chem. Phys. 124 (2010) 252-256

[21] N. Bellakhal, K. Draou, J.-L. Brisset, Plasma and wet oxidation of (63Cu37Zn) brass, Mater. Chem. Phys. 73 (2002) 235-241

[22] M.K. Abyaneh, L. Gregoratti, M. Amati, M. Dalmiglio, M. Kiskinova, Scanning Photoelectron Microscopy: a Powerful Technique for Probing Micro and NanoStructures, e-J. Surf. Sci. Nanotechnol. 9 (2011) 158-162

[23] H. Zhou, J. Qu, M. Cherkaoui, Finite element analysis of oxidation induced metal depletion at oxide-metal interface, Comp. Mater. Sci. 48 (2010) 842-847

[24] H. El Kadiri, M.F. Horstemeyer, D.J. Bammann, A theory for stress-driven interfacial damage upon cationic-selective oxidation of alloys, J. Mech. Phys. Solids 56 (2008) $3392-3415$

[25] Z.C. Xia, J.W. Hutchinson, Crack patterns in thin films, J. Mech. Phys. Solids 48 (2000) $1107-1131$ 


\section{CAPTIONS}

Figure 1: Map of as-grown nanostructures as a function of the radial distance for different thicknesses of the iron layer deposited onto the copper layer. $\mathrm{Fe}_{2} \mathrm{O}_{3}$ nanoblades are found as well as three different types of $\mathrm{CuO}$ nanostructures: nanowalls, nanotowers and nanowires. Caterpillar-like patterns induced by stress are observed in the colder part of the treated area (grey areas).

Figure 2: Evolution of the caterpillar-like patterns observed after treatment of a $900 \mathrm{~nm}$ $\mathrm{Fe} / \mathrm{Cu}$ coating as a function of the distance from the centre. Iron nanoblades appear as brighter (shown in circle). Other nanostructures are either $\mathrm{CuO}$ nanowalls, nanotowers or nanowires.

Figure 3: Examples showing caterpillar-like patterns observed after treatment and the way cracks can be distributed. a) Patterns without cracks. b) Large view of a $150 \mathrm{~nm} \mathrm{Fe} / \mathrm{Cu}$ coating after oxidation showing no correlation between cracks and patterns. c) Crack splitting a pattern in two and propagating in the film. d) Large view of a $900 \mathrm{~nm} \mathrm{Fe} / \mathrm{Cu}$ coating after oxidation showing a strong correlation between cracks and patterns.

Figure 4: a) SEM image of the $50 \mathrm{~nm} \mathrm{Fe} / \mathrm{Cu}$ coating before treatment. b) SEM image of the sample after oxidation $(+4500 \mu \mathrm{m}$ from the centre $)$.

Figure 5: a) SEM cross-section view of a single caterpillar-like pattern observed $1380 \mu \mathrm{m}$ from the treatment centre and showing the central channel through which the pattern is fed and grows radially. b) Another example of pattern observed $2500 \mu \mathrm{m}$ from the treatment centre c) SEM cross-section view of a single pattern observed $3500 \mu \mathrm{m}$ from the treatment centre and exhibiting an equiaxed grain structure. d) Detail of the topmost layer through which the pattern forms and below which a cell-like copper oxide layer is observed. Oxidation performed on a $155 \mathrm{~nm} \mathrm{Fe} / \mathrm{Cu}$ coating.

Figure 6: a) SEM cross-section view of a single caterpillar-like pattern observed $1750 \mu \mathrm{m}$ from the treatment centre. Oxidation performed on a $155 \mathrm{~nm} \mathrm{Fe} / \mathrm{Cu}$ coating. 
Figure 7: a) SEM cross-section view of a single caterpillar-like pattern observed $1750 \mu \mathrm{m}$ from the treatment centre. The main feeding channel is clearly visible. b) Detail of the transverse structure of the pattern. Regularly-spaced channels are also observed crosswise. Oxidation performed on a $155 \mathrm{~nm} \mathrm{Fe} / \mathrm{Cu}$ coating.

Figure 8: Normalized intensities of $\mathrm{Cu}$ (red line), Fe (black line) and $\mathrm{O}$ (blue line) SIMS signals as a function of the sputtering time for various radial distances. The $\mathrm{X}$-scale, expressed in sputtering time, was rescaled to set to 0 the position of the silica surface. SEM cross-section images showing the various layers corresponding to SIMS profiles. Oxidation performed on a $155 \mathrm{~nm} \mathrm{Fe} / \mathrm{Cu}$ coating.

Figure 9: X-ray diffraction patterns recorded every millimetres from the centre outward. No spinel phase is found.

Figure 10: a) A $100 \times 100 \mu \mathrm{m}^{2}$ map acquired at $\mathrm{Cu} 3 \mathrm{p}$ signal with a $648.5 \mathrm{eV}$ x-ray photon energy: and a 130-150 nm spot diameter. XPS spectra are acquired on two caterpillar-like patterns (points $\mathrm{N}$ and $\mathrm{P}$ ) and on the substrate (point $\mathrm{O}$ ) b) XPS spectra corresponding to points $\mathrm{N}, \mathrm{P}$ and $\mathrm{O}$ in the map. Oxidation performed on a $155 \mathrm{~nm} \mathrm{Fe} / \mathrm{Cu}$ coating $(+3000 \mu \mathrm{m}$ from the centre of the treatment).

Figure 11: a) $300 \mathrm{~nm} \mathrm{Fe} / \mathrm{Cu}$ coating deposited on silicon and covered by regularly-spaced cracks after bending. b) Image of the same area showing the presence of nanowires localized on the crack pattern. Inset: magnification showing the presence of nanowires in a crack. c) Example of another area where cracks form more complex patterns. d) Image of the same area showing the presence of nanowires localized on the crack pattern. Inset: magnification showing the presence of nanowires in a crack. 


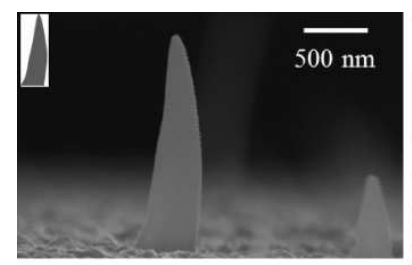

$\mathrm{Fe}_{2} \mathrm{O}_{3}$ nanoblades

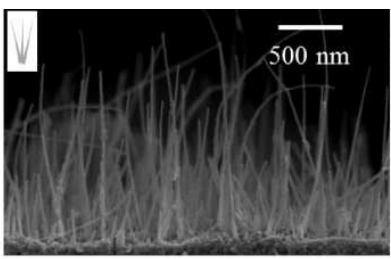

$\mathrm{CuO}$ nanowires

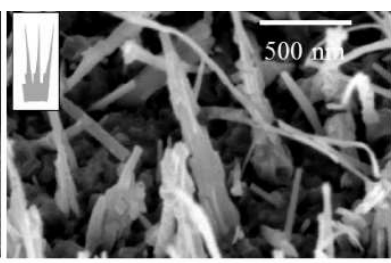

$\mathrm{CuO}$ nanotowers

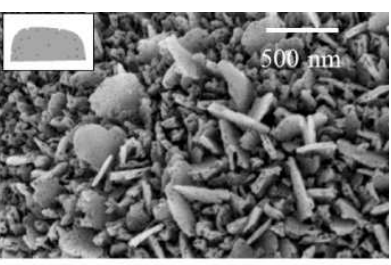

$\mathrm{CuO}$ nanowalls

Patterns
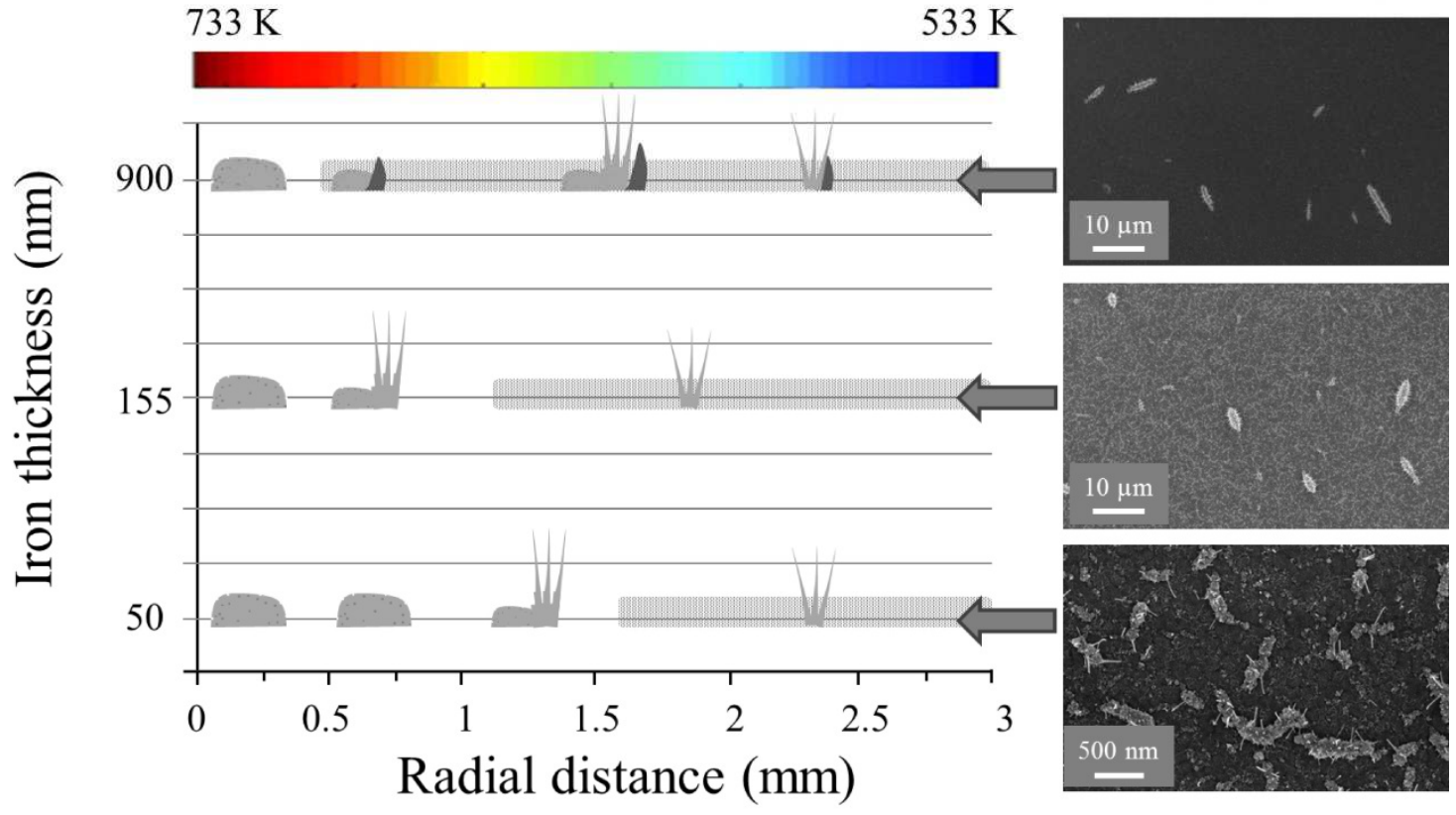

Figure 1: Map of as-grown nanostructures as a function of the radial distance for different thicknesses of the iron layer deposited onto the copper layer. $\mathrm{Fe}_{2} \mathrm{O}_{3}$ nanoblades are found as well as three different types of $\mathrm{CuO}$ nanostructures: nanowalls, nanotowers and nanowires. Caterpillar-like patterns induced by stress are observed in the colder part of the treated area (grey areas). 

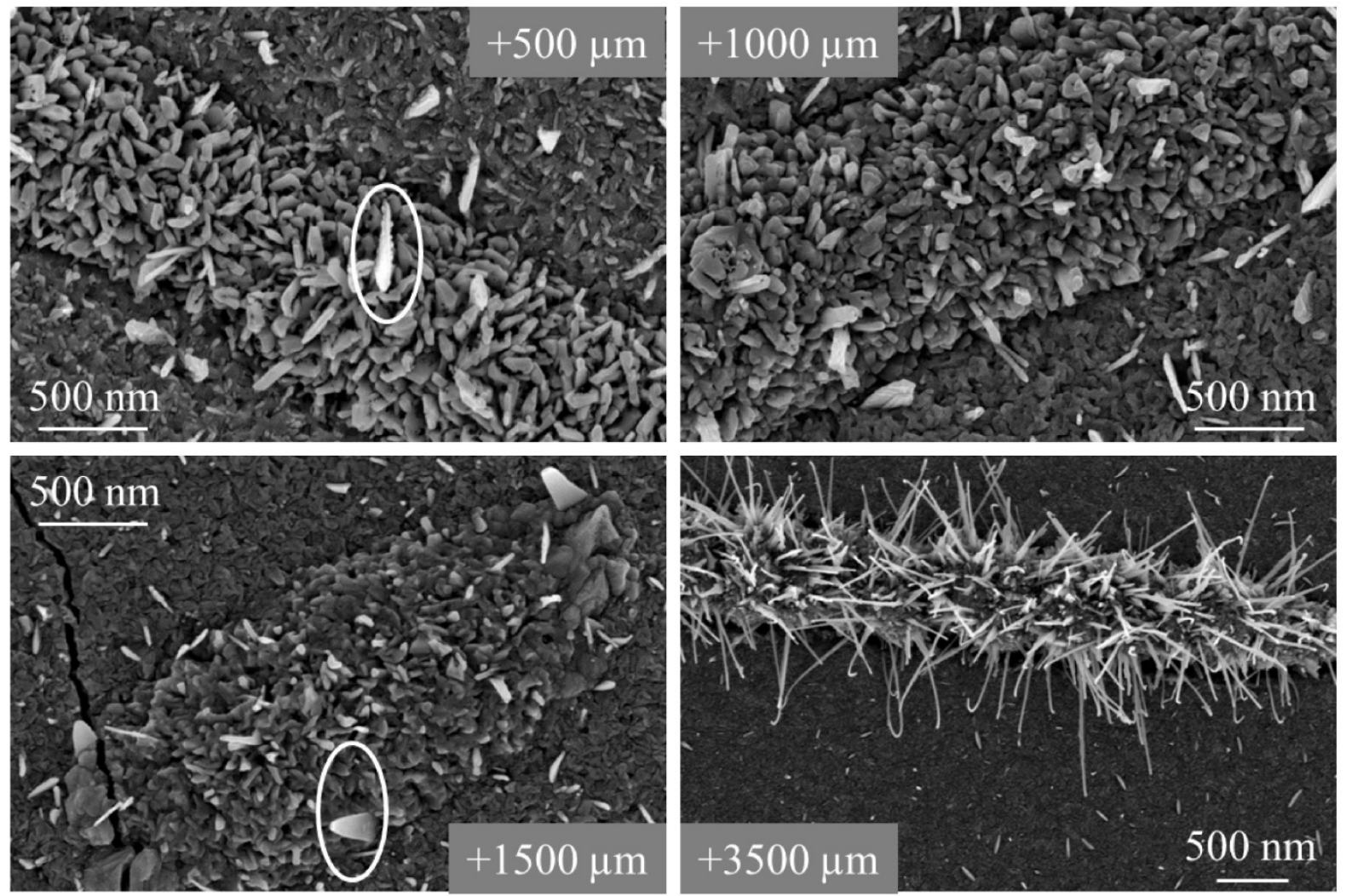

Figure 2: Evolution of the caterpillar-like patterns observed after treatment of a $900 \mathrm{~nm}$

$\mathrm{Fe} / \mathrm{Cu}$ coating as a function of the distance from the centre. Iron nanoblades appear as brighter

(shown in circle). Other nanostructures are either $\mathrm{CuO}$ nanowalls, nanotowers or nanowires. 

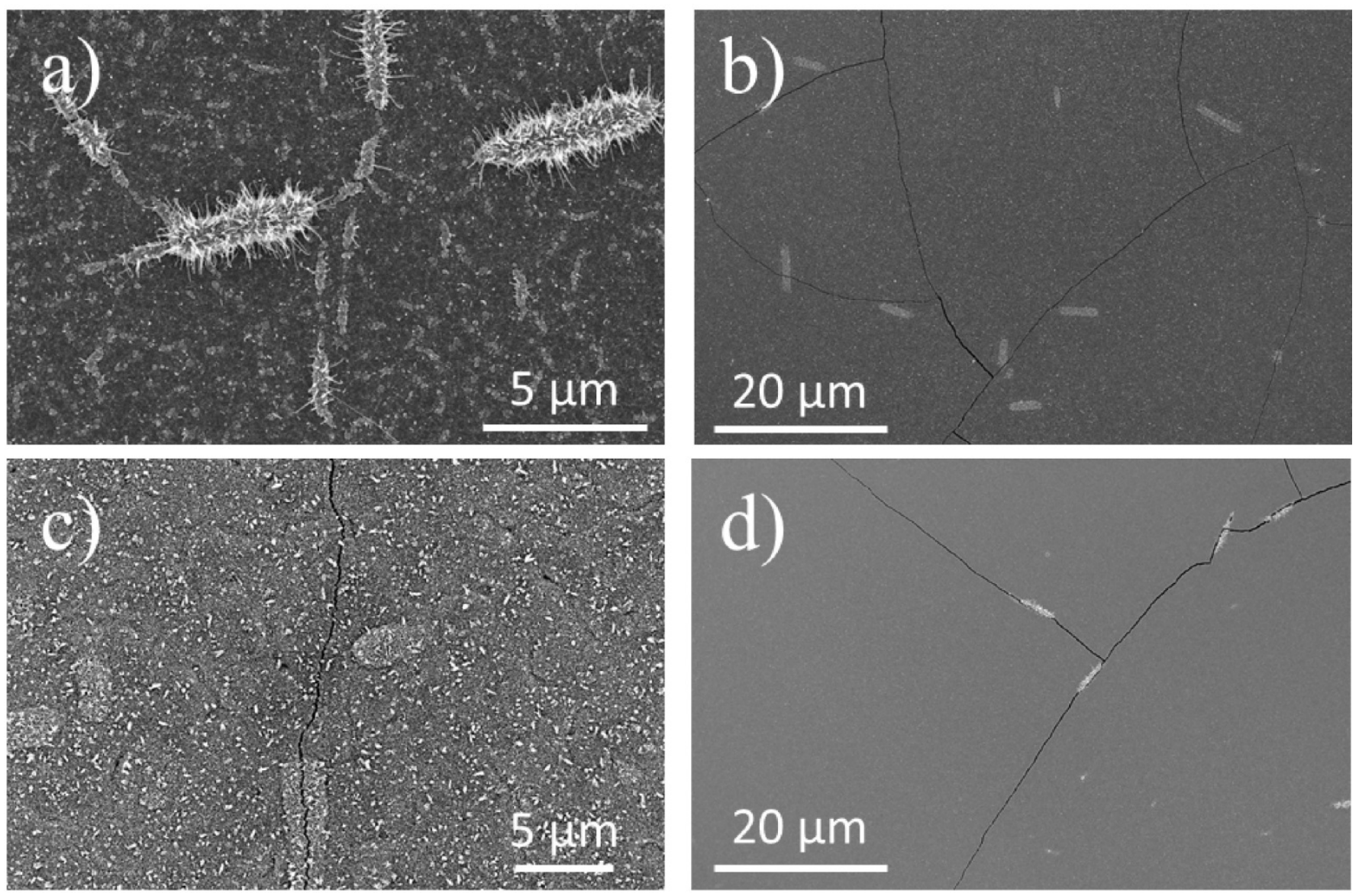

Figure 3: Examples showing caterpillar-like patterns observed after treatment and the way cracks can be distributed. a) Patterns without cracks. b) Large view of a $150 \mathrm{~nm} \mathrm{Fe} / \mathrm{Cu}$ coating after oxidation showing no correlation between cracks and patterns. c) Crack splitting a pattern in two and propagating in the film. d) Large view of a $900 \mathrm{~nm} \mathrm{Fe} / \mathrm{Cu}$ coating after oxidation showing a strong correlation between cracks and patterns. 


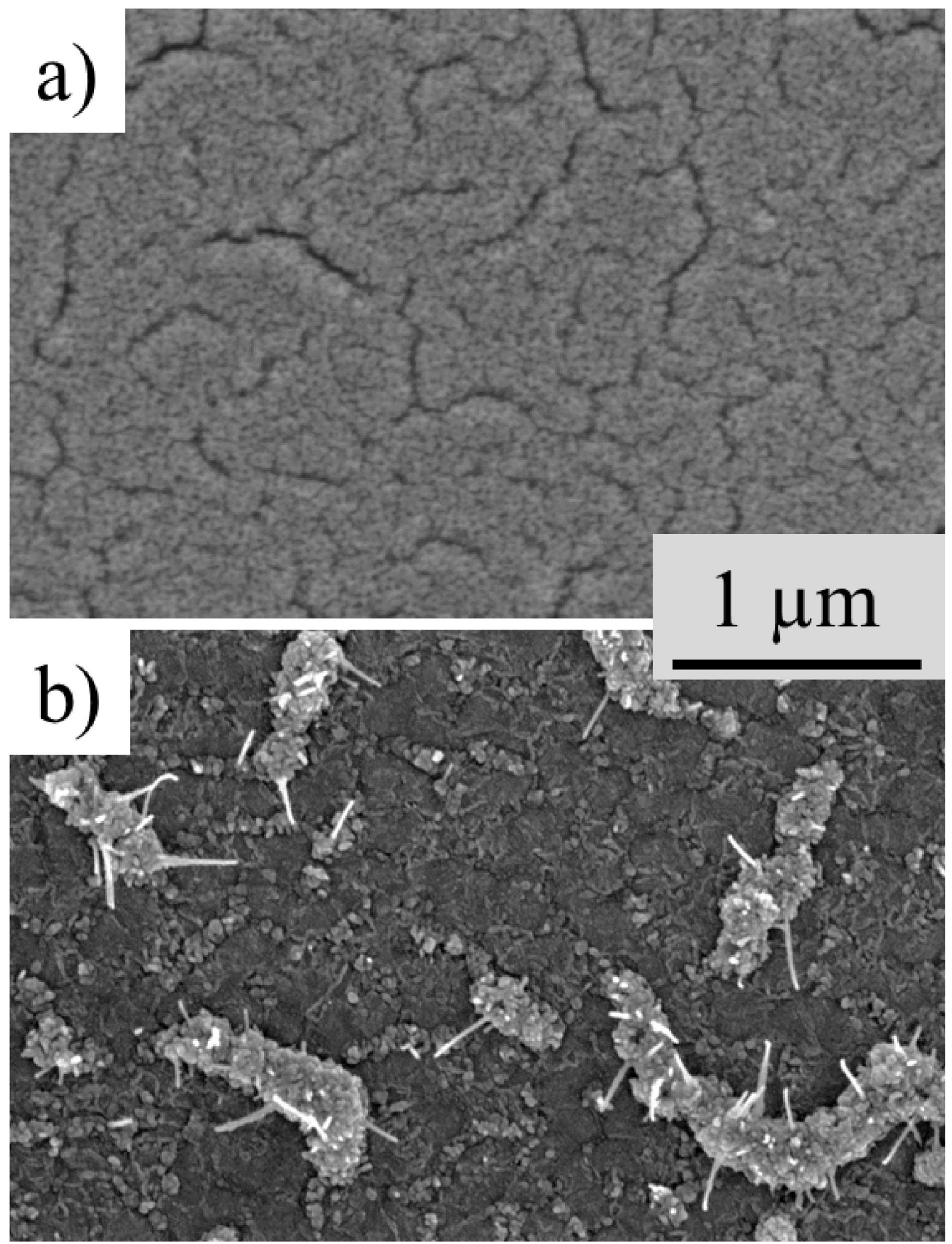

Figure 4: a) SEM image of the $50 \mathrm{~nm} \mathrm{Fe} / \mathrm{Cu}$ coating before treatment. b) SEM image of the sample after oxidation $(+4500 \mu \mathrm{m}$ from the centre $)$. 

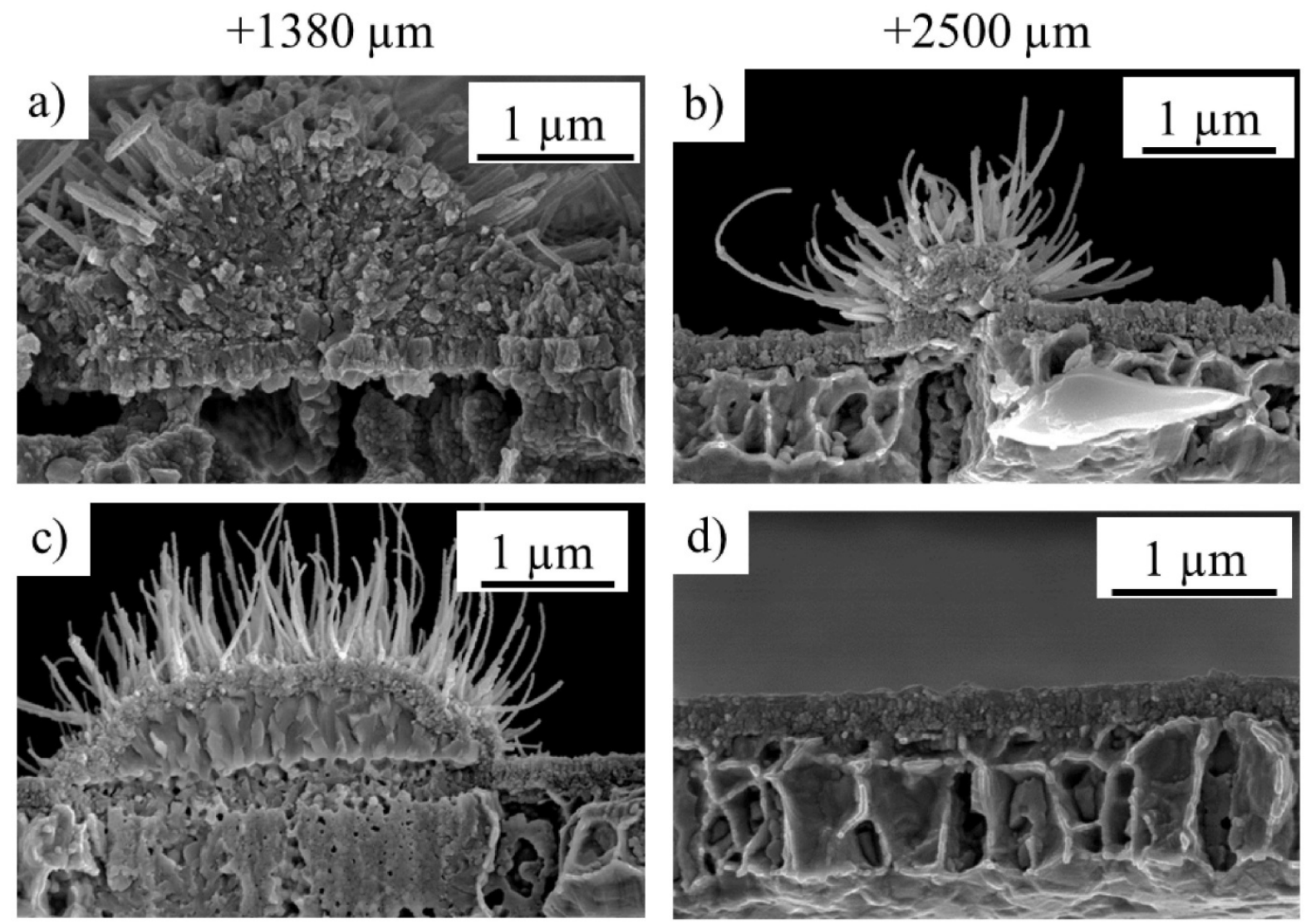

$+3500 \mu \mathrm{m}$

$+4000 \mu \mathrm{m}$

Figure 5: a) SEM cross-section view of a single caterpillar-like pattern observed $1380 \mu \mathrm{m}$ from the treatment centre and showing the central channel through which the pattern is fed and grows radially. b) Another example of pattern observed $2500 \mu \mathrm{m}$ from the treatment centre c) SEM cross-section view of a single pattern observed $3500 \mu \mathrm{m}$ from the treatment centre and exhibiting an equiaxed grain structure. d) Detail of the topmost layer through which the pattern forms and below which a cell-like copper oxide layer is observed. Oxidation performed on a $155 \mathrm{~nm} \mathrm{Fe} / \mathrm{Cu}$ coating. 


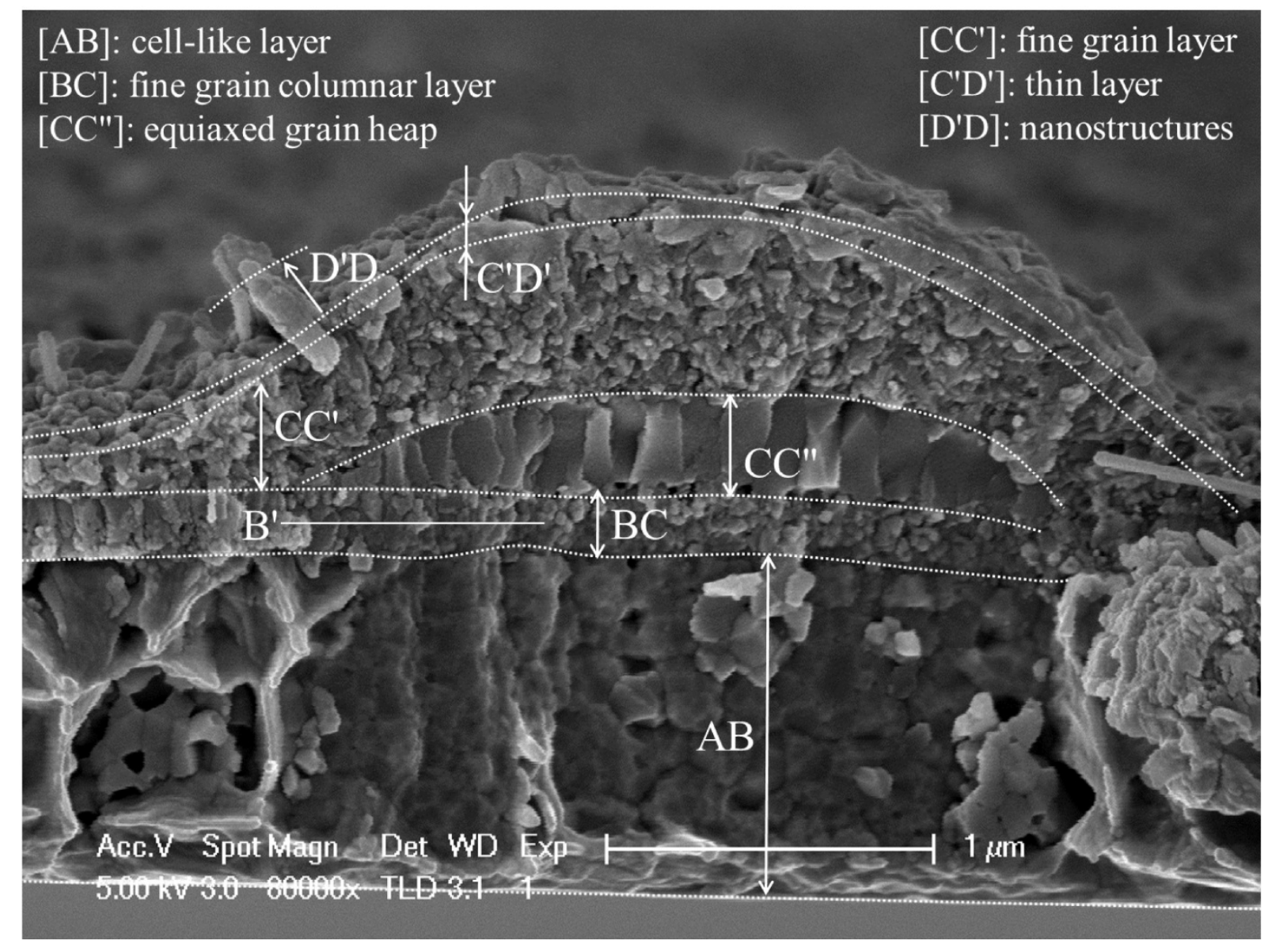

Figure 6: a) SEM cross-section view of a single caterpillar-like pattern observed $1750 \mu \mathrm{m}$ from the treatment centre. Oxidation performed on a $155 \mathrm{~nm} \mathrm{Fe} / \mathrm{Cu}$ coating. 

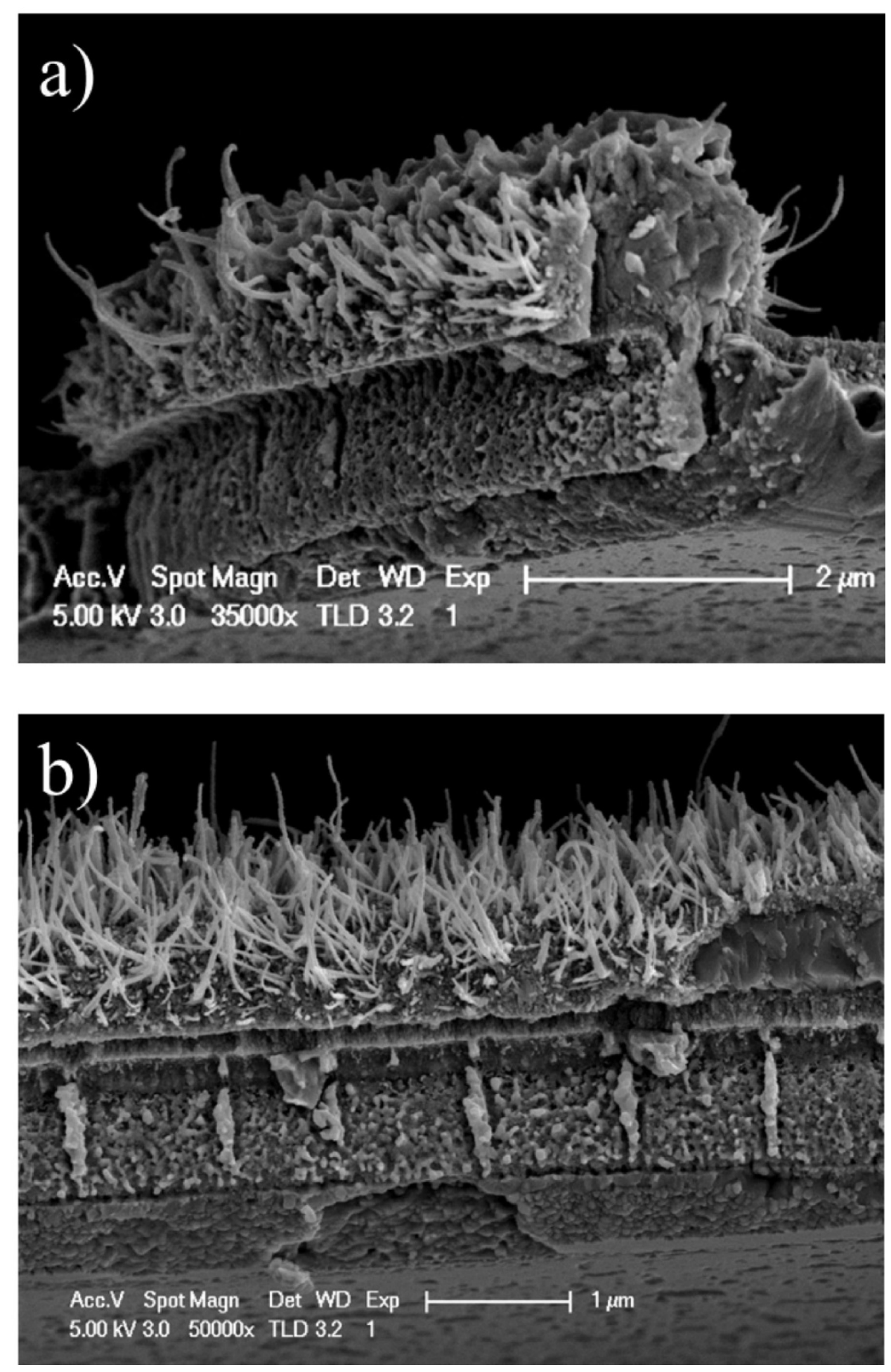

Figure 7: a) SEM cross-section view of a single caterpillar-like pattern observed $1750 \mu \mathrm{m}$ from the treatment centre. The main feeding channel is clearly visible. b) Detail of the transverse structure of the pattern. Regularly-spaced channels are also observed crosswise. Oxidation performed on a $155 \mathrm{~nm} \mathrm{Fe} / \mathrm{Cu}$ coating. 


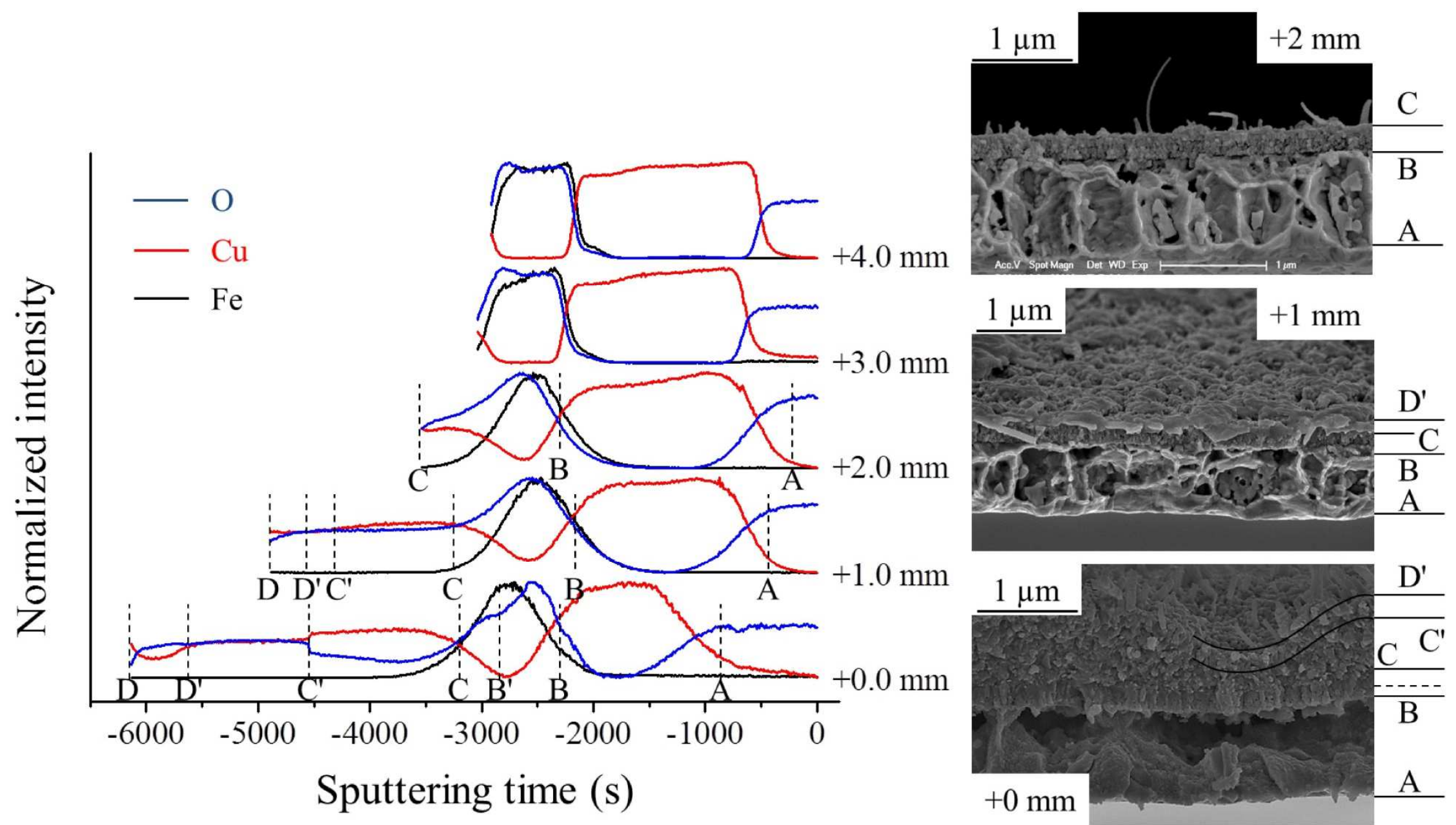

Figure 8: Normalized intensities of $\mathrm{Cu}$ (red line), Fe (black line) and $\mathrm{O}$ (blue line) SIMS signals as a function of the sputtering time for various radial distances. The $\mathrm{X}$-scale, expressed in sputtering time, was rescaled to set to 0 the position of the silica surface. SEM cross-section images showing the various layers corresponding to SIMS profiles. Oxidation performed on a $155 \mathrm{~nm} \mathrm{Fe} / \mathrm{Cu}$ coating. 


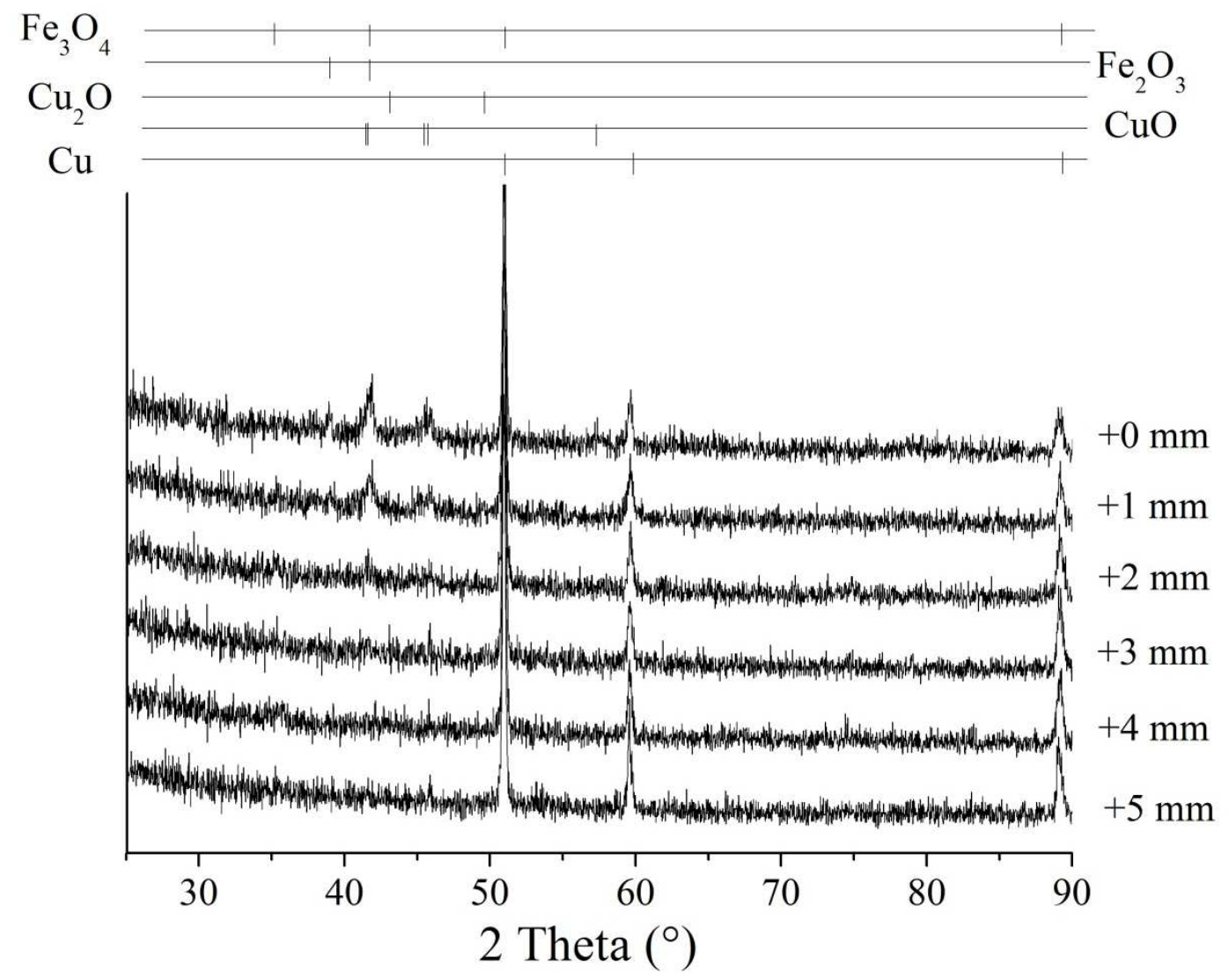

Figure 9: X-ray diffraction patterns recorded every millimetres from the centre outward. No spinel phase is found. 


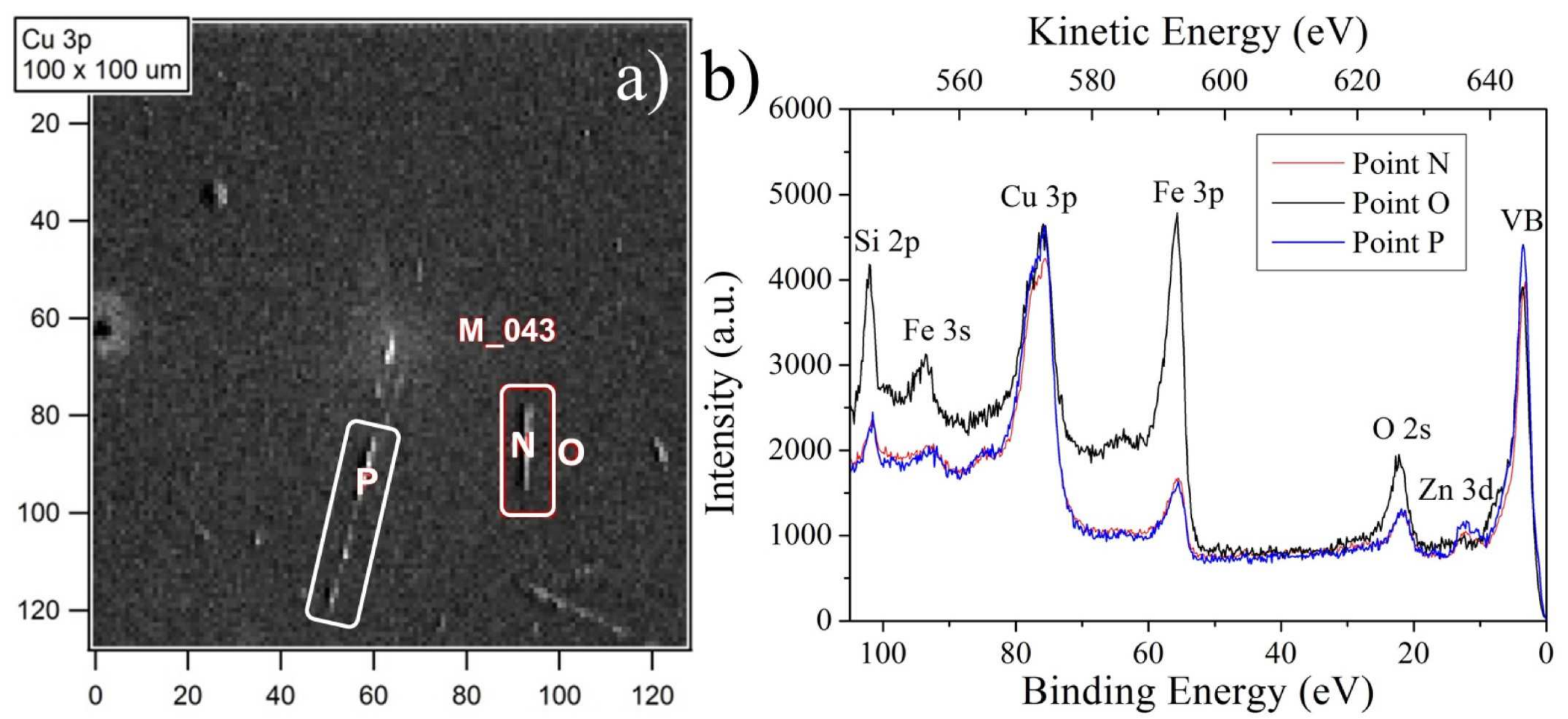

Figure 10: a) A 100x $100 \mu \mathrm{m}^{2}$ map acquired at $\mathrm{Cu} 3 \mathrm{p}$ signal with a $648.5 \mathrm{eV}$ x-ray photon energy: and a 130-150 nm spot diameter. XPS spectra are acquired on two caterpillar-like patterns (points $\mathrm{N}$ and $\mathrm{P}$ ) and on the substrate (point $\mathrm{O}$ ) b) XPS spectra corresponding to points $\mathrm{N}, \mathrm{P}$ and $\mathrm{O}$ in the map. Oxidation performed on a $155 \mathrm{~nm} \mathrm{Fe} / \mathrm{Cu}$ coating $(+3000 \mu \mathrm{m}$ from the centre of the treatment). 

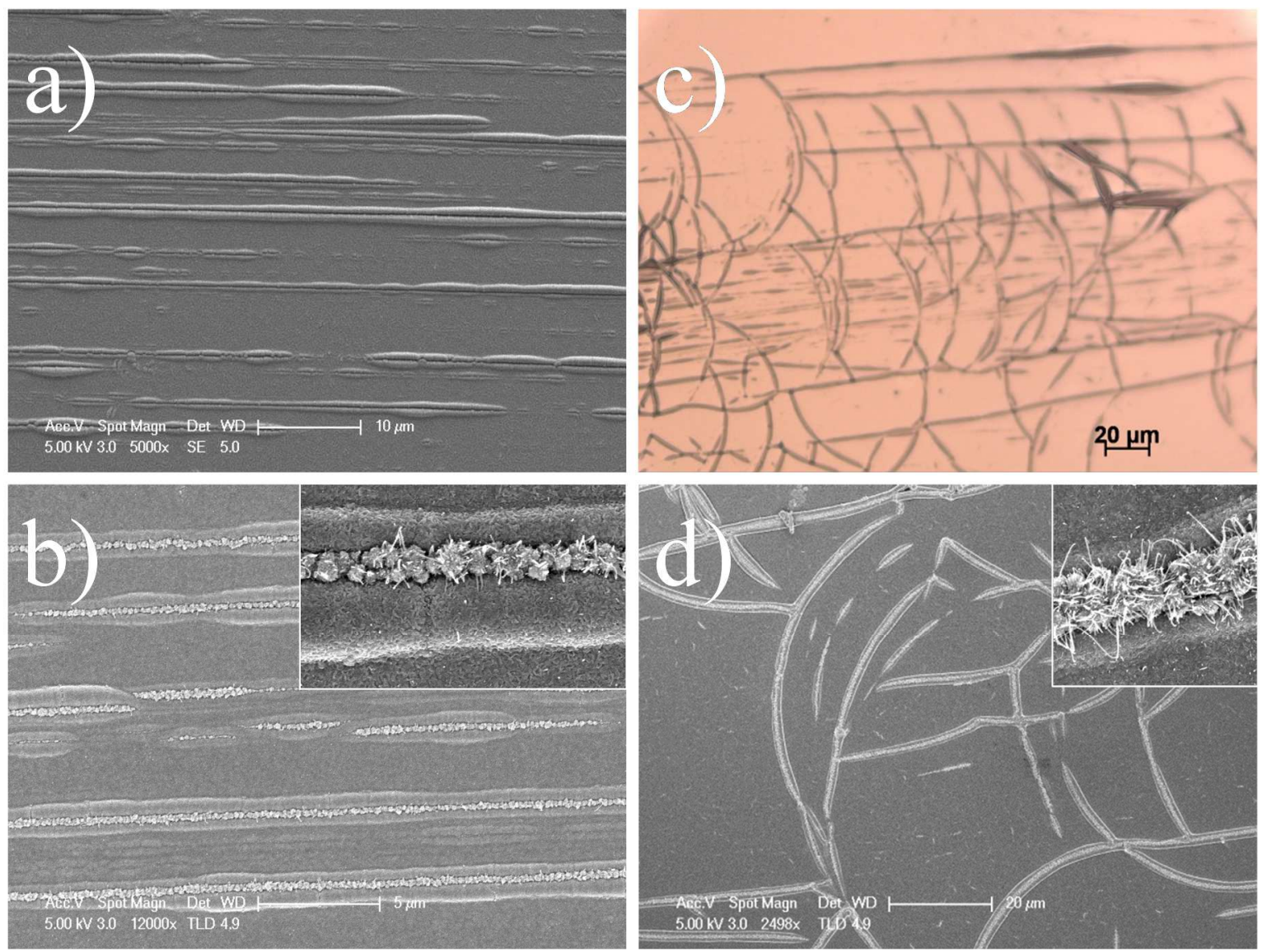

Figure 11: a) $300 \mathrm{~nm} \mathrm{Fe} / \mathrm{Cu}$ coating deposited on silicon and covered by regularly-spaced cracks after bending. b) Image of the same area showing the presence of nanowires localized on the crack pattern. Inset: magnification showing the presence of nanowires in a crack. c) Example of another area where cracks form more complex patterns. d) Image of the same area showing the presence of nanowires localized on the crack pattern. Inset: magnification showing the presence of nanowires in a crack. 